\title{
Spreadsheet Model for Determining Adequate Performance Indicators of Production Management
}

DOI: 10.7595/management.fon.2020.0011

Abstract:

Research Question: This paper presents a simulation model aimed at improving total adequacy calculation for performance indicators of the first phase of production management. Motivation: Defining a set of adequate performance indicators that are specific and highly important for the observed planning phase has a significant impact on the effectiveness of the production process management. The result of the developed model is the value of selected performance indicators adequacy. Consequently, it can be concluded whether defined performance indicators are essential for the observed phase or other performance indicators should be selected. The monitoring of defined performance indicators should provide complete information about the observed phase and improvement of the planning phase management. Idea: The main idea of this paper is to develop a user-friendly simulation model, in accordance with the basic principles of spreadsheet engineering, for improving the selection of adequate performance indicators. This model is intended for use in Small and Medium Enterprises (SMEs) for the improvement of production management. Data: The data used in the paper are grounded on the scientific articles, reviews and empirical studies, related to the performance and performance indicators in production management. The set of most adequate performance indicators based on a relevant literature review and used in the model, represents performance indicators for the planning phase that are the most suitable for SMEs. Tools: The simulation model is developed in a spreadsheet environment. The use of spreadsheet applications enables simple data entry, processing, editing, analyzing and output reports compiling. Findings: Simulation results show the overall efficiency of the developed model in the determination of adequate performance indicators. They influence overall adequacy of performance indicators on the observed phase. Contribution: The main contribution of this paper lies in the model developed to maximize the adequacy of the performance indicators, suitable for use in the production management of SMEs.

Keywords: Production management, Production planning, Adequate performance indicators, Simulation model, Spreadsheet engineering

JEL Classification: M11, C63

\section{Introduction}

With constant changes in market conditions in today's competitive business environment, every manufacturing company needs to define the performance and performance indicators, to measure them and to monitor their values. Based on these values, the enterprise should monitor business results and correct control actions. Determining a set of adequate performance indicators of production management represents a complex and demanding activity. The selection of a set of adequate performance indicators for production management phases depends on the quality and validity of the information they provide, where the total adequacy of performance indicators should reach maximum value (Rajkovic, Makajic-Nikolic, Vujosevic, \& Lecic-Cvetkovic, 2019). The purpose of this paper is to develop a model for defining a set of adequate performance indicators for one phase of production management. This model is based on the main principles of spreadsheet engineering. The paper analyses adequate performance indicators of planning in Small and Medium Enterprises (SMEs) in the manufacturing industry, as the first phase of production management. A SME's business is usually characterized by insufficient funds for software solution development and its im- 
plementation represents a striking characteristic of a SME's business (Zach, Munkvold, \& Olsen, 2014). Consequently, the authors of the paper suggest a spreadsheet simulation model, whose implementation is not expensive and which end-users can relatively easily apply. Spreadsheet models are widely available and suitable for end-users, as well as for domain experts with a modest level of spreadsheet programming skills. Spreadsheets represent a flexible and functional tool that supports simulation, decision-making processes and the analysis of the environment from many different perspectives (Djordjevic, 2017). In addition, they represent a custom tool for problem-solving, which is easier to develop and implement than other tools, while significantly low cost of these activities indicates other essential benefits (Teixeira \& Amaral, 2016).

The remainder of this paper is organized as follows. The second chapter briefly describes the implementation of spreadsheet engineering principles in the production management of SMEs; it explicates characteristics of spreadsheets and spreadsheet control models and their implications in production management; finally, it explains adequate performance indicators and total adequacy of performance indicators. The third chapter expounds the model created for the calculation of adequacy of selected performance indicators for one phase of production management and presents simulation results. The fourth chapter outlines final remarks and directions for future research.

\section{Performance Indicators and Spreadsheet Engineering in Production Management}

Production management can be defined as the management of the transformation process of inputs into outputs (Gupta \& Starr, 2014). The main purpose of the production process is the production of a certain quantity of products with defined all required manufacturing steps, including standard, minimal costs, defined timeline, and projected quality (Halevi, 2001; Rajkovic \& Lecic-Cvetkovic, 2018). The production process consists of four phases (Omerbegovic-Bijelovic, 2006; Gupta \& Starr, 2014; Todorovic, 1993): planning, organizing, implementation and control. A contemporary business environment implies a constant development of products/services, improvement of production processes, supply and distribution, maintenance of stocks of raw materials and (semi) products, as well as the improvement of the management process by using new methods and techniques of enterprise management (Atanasov, Rakicevic, Lecic-Cvetkovic, \& Omerbegovic-Bijelovic, 2014).

Performance indicators are a powerful tool for understanding the adequacy of business and identifying problematic areas, which presents an integral part of proper management and professional practice (Simeunovic, 2015). They are used to report on results concerning enterprise objectives and targets (Gudmundsson, Marsden, \& Josias, 2016). Performances identification comprises identification of performance indicators, measurement methods, benchmarks for comparison of results, as well as the source and reliability of the data used. For the performance identification process, it is essential to define adequate performance indicators. The decision-making process and actions are greatly influenced by indicators nature, use and time horizon (short or long-term) (Franceschini, Galetto, \& Maisano, 2019). The selection of adequate performance indicators is a critical point in the process of translating an enterprise mission into a business strategy and relevant objectives, which means that performance indicators are an integral part of a production management strategy (Atanasov, 2016). Adequate performance indicators are used to measure benefits for enterprise networks and should correspond to its size, processes and activities (Graca \& Camarinha-Matos, 2017). The complexity of defining the adequate performance indicators stems from the necessity of their reliability and the meaningfulness of the information they provide (Dajic \& Todic, 2017). The adequate performance indicators should be sensitive to changes, adequate for the current state of a system process, and easily calculated. The authors (Villa \& Taurino, 2018) consider that one of the most critical problems for managers in SMEs is related to production. The reason is that multiple tasks need to be accomplished with limited resources and machines, a lack of technology, resources, awareness, and knowledge of production management.

For the purpose of this paper, the adequate performance indicators are considered as a group of the most important performance indicators for the planning phase. Selected performance indicators should be those with the highest total adequacy for the observed phase. The total adequacy represents a cumulative value of all weights of performance indicators defined for the planning phase. The objective is to achieve the highest value of the total adequacy which means that the selected performance indicators are entirely adequate for the observed phase. This value indicates that a set of adequate performance indicators has an important impact on the observed phase and enables continuous improvement to achieve a more efficient and effective production management. One of the objectives of a manufacturing company is to ensure a stable production management. This objective can be achieved by the application of a spreadsheet control mod- 
els. The usability and overall rules for creating spreadsheet models depend on many factors, such as the purpose of the model, the complexity and dimensions of the problem being modelled, the knowledge and experience of the creator, etc. (Antic \& Djordjevic, 2018).

A spreadsheet model can be represented as a set of algebraic equations implemented in a spreadsheet environment. Spreadsheet control models implement a mathematical model, which reflects the domain of an expert's knowledge and experience (Djordjevic, 2016). Like any other, a spreadsheet model uses a set of inputs and calculates a set of outputs (Antic \& Djordjevic, 2018). Spreadsheet programmes are probably the most successful example of end-user software development tools, used for a variety of purposes (Jannach \& Schmitz, 2016). Users can analyze decision alternatives before having to choose a specific plan for implementation in an enterprise (Ragsdale, 2018). According to (Djordjevic, 2017) modern spreadsheets are categorized as end-users programming languages (i.e., End-User Computing - EUC) for non-professional developers. In order to develop and ensure the quality of spreadsheet models and applications that are efficient, effective, portable, and adequately documented, it is necessary to apply spreadsheet engineering knowledge. Spreadsheet engineering can be explained as the application of software engineering principles to spreadsheets. It deals with various aspects of spreadsheet design and implementation, i.e., the life cycle of spreadsheet models and applications (Djordjevic, 2017). Djordjevic (2017) defines software engineering as a broad field that covers various techniques, for example: design before programming, modular structure, data referencing, documentation, etc. Many of these techniques are directly applicable to spreadsheets and define spreadsheet engineering. Adoption and application of the spreadsheet engineering principles have the potential to solve some of the basic problems related to spreadsheets: poor design, poor modularity, mixed data and calculations, lack of documentation, etc.

Although spreadsheets have countless advantages, they are also characterized by numerous errors (Djordjevic, 2017). Errors occur due to the omission of the testing phase and the lack of professional programming knowledge of the spreadsheet creators (Djordjevic, 2016). The authors (Hermans, Jansen, Roy, Aivaloglou, Swidan, \& Hoepelman, 2016) define the following issues related to spreadsheets: long life span, many different users performing a variety of tasks, lack of documentation and quality issues (substantial impact of errors involving spreadsheets). The authors (Broman \& Woo, 2018) define basic principles for organizing spreadsheet data in order to reduce errors and facilitate analyses: be consistent, do not leave any cells empty, put just one thing in a cell, organize the data as a single rectangle (with subjects as rows and variables as columns, and with a single header row), create a data dictionary, do not include calculations in the raw data files, do not use font colour or highlighting as data, make backups, use data validation to avoid data entry errors, and save the data in plain text files. According to (Djordjevic \& Antic, 2014) each spreadsheet model should comprise: modular and structural design, information flows, the range of field for input and output data, calculation module, and a reporting part.

\section{A Spreadsheet Model Based on Adequate Performance Indicators}

Most users do not apply spreadsheet engineering principles because of the lack of experience or training (Roy, Hermans \& van Deursen, 2017). Consequently, it is important to develop a standardized model that can be easily implemented in everyday business activities. The model should be easy to understand and quickly accepted by end-users.

\subsection{Problem description}

The problem of selecting a set of adequate performance indicators for production management is a complex task, which can be solved by choosing a set of adequate performance indicators for each stage of production management. The model presented in this paper assumes a set of performances for the first stage of production management, defined to monitor the success of this phase. For the purpose of this research, four different performances and eight performance indicators of the planning phase are defined. Selected performances and performance indicators are chosen in accordance with the problems usually appearing and mostly affecting everyday business activities of SMEs. The selection is grounded on the research presented in (Franceschini, Galetto, \& Maisano, 2006) and encompasses the following: the indicators should not be too complex, in order to avoid overloading the employees with work, the indicators should be easily understood and effectively used, they should have a clear distinct feature to be largely accepted by the employees, and necessary information should be available. The main objective is to select the group of adequate performance indicators of the highest importance for the observed phase. Additionally, the performances and performance indicators used for the model development are defined based on the liter- 
ature review (Amrina \& Vilsi, 2015; Bauer \& Hayessen, 2015; Bhatti, Awan, \& Razaq, 2014; Gomes, Yasin, \& Lisboa, 2011; Gosselin, 2005; Kang, Zhao, Li, \& Horst, 2016; Muchiri, Pintelon, Gelders, \& Martin, 2011; Tewari, Singh, \& Tewari, 2016). The most cited ones are selected as the most monitored in the planning phase in SMEs operating in the manufacturing industry.

The most significant performances for the observed phase used in the simulation are the following: Cooperation with suppliers, Cooperation with customers, Machine performances, and Cost performances. Performance indicators defined for considered performances are presented as follows. For performance Cooperation with suppliers, performance indicators are: Delivery time, Defect of delivered raw materials, and Mistakes and omissions; for performance Cooperation with customers, performance indicators are: Delivery time and Service; for performance Machine performances, performance indicators are: Mistakes and omissions, Service, and Available capacity of machines; for performance Cost performances, performance indicators are: Mistakes and omissions, Planned production costs (per product unit), Planned labour costs, and Planned material/raw material costs. It is important to note that one performance indicator can be an indicator of more performances.

Table 1 shows the weight coefficients of performance indicators per performance. The weights are defined according to the importance of performance indicators for the observed performance. In practice, these weights are defined by a production manager or a planner, who monitors performance indicators of SMEs. In this paper, the values were defined by the authors of the paper and entered in columns Cooperation with suppliers, Cooperation with customers, Machine performances and Cost performances. The Porter scale (05 ) is used for the performance indicator weight estimation. Value 0 presents the lowest significance of the indicator for the observed performance, and value 5 represents the highest significance of the indicator for the observed performance. For example, performance indicator Delivery time has a value 3 for the performance Cooperation with suppliers and a value 5 for the performance Cooperation with customers, but a value 0 for Machine and Cost performances. For the performance Cooperation with customers, this performance indicator has a great significance, but it is not a performance indicator for Machine and Cost performances. The weights of performance indicators per performance differ and clearly define the priority of performance indicators. Performance indicators per performance are ranked according to their weights in descending order.

Table 1: Weights of performance indicator per performance for the planning phase and their ranks

\begin{tabular}{|c|c|c|c|c|c|c|c|c|}
\hline $\begin{array}{l}\text { Performance } \\
\text { indicators }\end{array}$ & 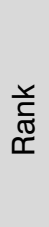 & 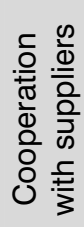 & 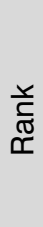 & 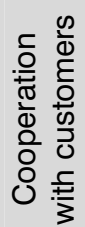 & $\begin{array}{l}\underset{r}{\mathbb{C}} \\
\underset{\simeq}{\simeq}\end{array}$ & 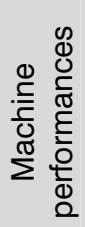 & 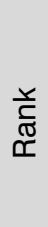 & 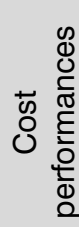 \\
\hline Delivery time & 3 & 3 & 1 & 5 & 4 & 0 & 5 & 0 \\
\hline Defect of delivered raw materials & 1 & 5 & 3 & 0 & 4 & 0 & 5 & 0 \\
\hline Mistakes and omissions & 2 & 4 & 3 & 0 & 2 & 4 & 4 & 2 \\
\hline Service & 4 & 0 & 2 & 4 & 3 & 3 & 5 & 0 \\
\hline Available capacity of machines & 4 & 0 & 3 & 0 & 1 & 5 & 5 & 0 \\
\hline $\begin{array}{l}\text { Planned production costs (per product } \\
\text { unit) }\end{array}$ & 4 & 0 & 3 & 0 & 4 & 0 & 3 & 3 \\
\hline Planned labor costs & 4 & 0 & 3 & 0 & 4 & 0 & 2 & 4 \\
\hline Planned material/raw material costs & 4 & 0 & 3 & 0 & 4 & 0 & 1 & 5 \\
\hline
\end{tabular}

\subsection{Mathematical formulation}

In order to explain the spreadsheet simulation model for the performance indicators adequacy maximization, the following notations are used:

- $P_{n}$ : performances of the planning phase, $n=1, \ldots, 4$;

- $P I_{k}{ }^{P n}$ : performance indicator per performance, $n=1, \ldots, 4 ; k=1, \ldots, 4$;

- $P I_{P n}$ : number of performance indicators per performance, $n=1, \ldots, 4$;

- $W_{P I K}^{P n}$ : weight coefficient of performance indicator per performance, $n=1, \ldots, 4 ; k=1, \ldots, 4$;

- $C$ : minimum weight of performance indicator;

- $A P I_{\text {min }}$ : minimum number of adequate performance indicators for the phase (where $A P I_{\min }{ }^{n}$ is for $P_{n}$, $n=1, \ldots, 4)$; 
- $A P I_{\text {max }}$ : maximum number of adequate performance indicator for the phase (where $A P I_{\max }{ }^{P n}$ is for $P_{n}$, $n=1, \ldots, 4)$;

- $A P I_{P n}$ : number of adequate performance indicators for observed performance according to the constraint $C, n=1, \ldots, 4$

- $u_{P_{n}}$ : number of adequate performance indicators $A P I_{P n}$;

- $X_{P n}$ : state variable defining total adequacy of performance indicators for the observed phase;

- $Y_{P n}$ : adequacy of performance indicators per performance according to the number of defined $u_{P n}$.

The user of this model defines constraint $C$. The minimum and maximum value of $C$ is shown by inequality (1), according to the Porter scale.

$$
0 \leq C \leq 5
$$

The value of $P I_{P n}$ is defined in advance and entered as an input value (Table 2). Values for $A P I_{P n}$ are defined as a number of performance indicators $P I_{P n}$ that fulfill the defined constraint $C$. The value $A P I_{P n}$ must be between the minimum and the maximum of a defined number of adequate performance indicators for the planning phase (2). The minimum and maximum values are defined by the user.

$$
A P I_{\min } \leq A P I_{P n} \leq A P I_{\max }
$$

The control variable $\left(u_{P n}\right)$ represents the number of adequate performance indicators for the observed performance. This value must be between the minimum and the maximum number of adequate performance indicators for considered performance. The control domain is defined by three constraints (3-5).

$$
\begin{gathered}
u_{P n}-A P I_{\text {min }} \geq 0 \\
A P I_{\text {max }}-u_{P n} \geq 0 \\
A P I_{P n} \geq u_{P n}
\end{gathered}
$$

Variable $Y_{P_{n}}$ represents the sum of weights of adequate performance indicators per performance, according to the $u_{P n}$. For example, rank 1 implies a performance indicator with the highest weight value, rank 2 has a performance indicator with the next weight value (in descending order), etc. This affects the change of order of performance indicators per performance, where the performance indicator takes place according to the ranked value (equation 6).

$$
P I_{k}^{P n}=P I_{r}^{P n}, r=1, \ldots, 4 ; k=1, \ldots, 4
$$

The control variable $u_{P_{n}}$ defines the number of performance indicators per performance for which the weight will be summed and presented as $Y_{P_{n}}$. Variable $Y_{P_{n}}$ sums weights of performance indicators starting from rank 1 until the rank that has the same value as $u_{P_{n}}$ (equation 7).

$$
Y_{P n}=\sum_{r=1}^{u_{P_{n}}} W_{P I}^{P_{n}}, n=1, \ldots, 4
$$

Variable $X_{P n}$ represents a system state, i.e., total adequacy of performance indicators for the planning phase, shown in equation (8).

$$
X_{P n}=X_{P n-1}+Y_{P n}, n=1, \ldots, 4
$$

The variable $X_{P n}$ reflects the adequacy level of the performance indicators. The value of this variable represents the total adequacy of performance indicators for the planning phase, as the cumulative value of all weights of performance indicators defined by the control variables. Based on this value, it can be deduced whether the chosen performance indicators are adequate for the observed performance. If not, the production manager, or a planner, will have to define performance indicators that are more significant for the observed performance. The objective function $J$ represents the sum of variables $X_{P_{n}}$ and it should be maximized for all performance indicators (9). The total value of this objective function should achieve the maximum value, which implies that the observed set of performance indicators is adequate for the planning phase.

$$
\text { (max) } J=\sum_{n=1}^{4} X_{P n}, n=1, \ldots, 4
$$

For the observed model, the minimum adequacy value is 0 (if $A P I_{\min }=0$ ), whereas the maximum adequacy value is 47 (if $A P I_{\max }=4$ ). 


\subsection{The model implementation and simulation results}

The described performance indicators adequacy model is implemented in a spreadsheet environment Microsoft Excel (Figure 1). The legend of terms and abbreviations used in the spreadsheet model is the following: $P I(P)$ is the number of performance indicators for the planning phase; $P I(P n)$ represents the number of performance indicators per performance; $A P I(P)$ is the number of adequate performance indicators per planning phase and $A P I(P n)$ relates to the number of adequate performance indicators per performance. The developed spreadsheet model is characterized by a modular design presented through three top-level modules: input, calculation, and output modules. The input module is intended for storing input data (circumstance and control variables), entered by the user. The calculation module is used for the mathematical model implementation. The report module represents the results reflected through the objective function, which determines the quality of control.

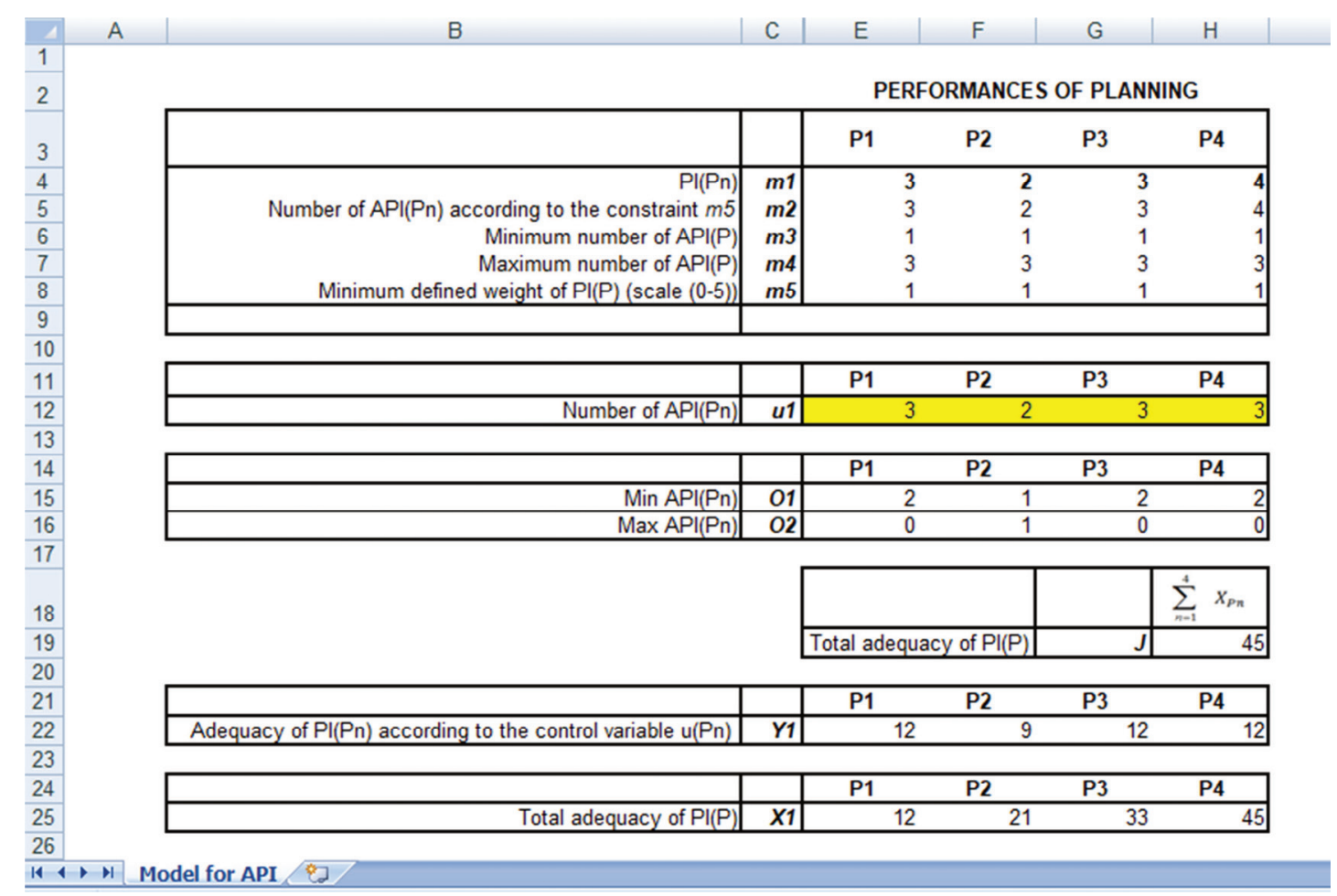

Figure 1: The spreadsheet model for performance indicators adequacy maximization

The application of structural design affects the readability (separated input, output and calculation modules), accuracy (provided by translating the verbal model into mathematical and mathematical into a spreadsheet model, applied conditional formatting and data validation), reusability (it can be used again and with different data), and modification of the model (each module can be modified to reflect the newest facts, without influencing other modules) (Grossman, Mehrotra, \& Sander, 2011). The model structure comprises the logic of the input and output modules and organized information flows. The inputs and outputs of the model are separated, without the distractions caused by the calculation, and represent sets of connected blocks. Information flows are direct and non-intersectional. At the highest level, information flows start from the input data $\left(P I_{P n}, A P I_{P n}, A P I_{\min }, A P I_{\text {max }}, C, u_{P n}\right)$, continue through the calculation section, and end with the output values $\left(X_{P_{n}}, J_{P_{n}}\right)$. This structure, based on the principles of spreadsheet engineering, reduces the likelihood of errors and improves the functionality of the created model. Arranged information flows allow the model to be easily modified by changing the part for calculations, with the input and output parts isolated.

The simulation is conducted for the planning phase of production management and four performances of that phase. The control variable values are changed according to the constraint (5). Three scenarios with different input data were analyzed (Table 2). According to the value of the objective function, the user of this model can deduce whether the set of performance indicators is adequate for the observed phase. A low value of the objective function implies that new performance indicators should be defined for the observed phase.

The simulation result will be explained for the second scenario (Table 2). The performance indicators per performance were defined and explained in section 3.1. Based on the constraints, the minimum observed weight 
is $C=3$, the minimum number of adequate performance indicators for the phase is $A P I_{\min }=1$ and the maximum number of adequate performance indicators for the phase is $A P I_{\max }=3$. It is needed to define the number of adequate performance indicators per performance that meets those constraints and strives to maximize the adequacy of performance indicators for the planning phase. Results of the model simulation are:

- Performance Cooperation with suppliers has three $\left(u_{P 1}=3\right)$ adequate performance indicators (Defect of delivered raw materials, Mistakes and omissions and Delivery time), where the weight of performance indicators per this performance is $Y_{P 1}=12$;

- Performance Cooperation with customers has two $\left(u_{P 2}=2\right)$ adequate performance indicators (Delivery time and Service), where the weight of performance indicators per this performance is $Y_{P 2}=9$;

- Machine performance has three $\left(u_{P_{3}}=3\right)$ adequate performance indicators (Available capacity of machines, Mistakes and omissions and Service), where the weight of performance indicators per this performance is $Y_{P_{3}}=12$;

- Cost performance has three $\left(u_{P 4}=3\right)$ adequate performance indicators (Planned material/raw material costs, Planned labor costs and Planned production costs (per product unit)), where the weight of performance indicators per this performance is $Y_{P 4}=12$.

The total adequacy of these performance indicators for the planning phase is 45 .

Table 2: Input data and simulation results of the implemented spreadsheet model

\begin{tabular}{|c|c|c|c|c|c|c|}
\hline Scenario & Data Performance & $P_{1}$ & $P_{2}$ & $P_{3}$ & $P_{4}$ & $\boldsymbol{J}$ \\
\hline \multirow{8}{*}{1} & $P I_{P n}$ & 3 & 2 & 3 & 4 & \multirow{8}{*}{36} \\
\hline & $A P I_{P n}$ & 2 & 2 & 2 & 2 & \\
\hline & $A P I_{\min }$ & 1 & 1 & 1 & 1 & \\
\hline & $A P I_{\max }$ & 2 & 2 & 2 & 2 & \\
\hline & C & 4 & 4 & 4 & 4 & \\
\hline & $u_{P n}$ & 2 & 2 & 2 & 2 & \\
\hline & $X_{P n}$ & 9 & 18 & 27 & 36 & \\
\hline & $Y_{P n}$ & 9 & 9 & 9 & 9 & \\
\hline \multirow{8}{*}{2} & $P I_{P n}$ & 3 & 2 & 3 & 4 & \multirow{8}{*}{45} \\
\hline & $A P I_{P n}$ & 3 & 2 & 3 & 3 & \\
\hline & $A P I_{\min }$ & 1 & 1 & 1 & 1 & \\
\hline & $A P I_{\max }$ & 3 & 3 & 3 & 3 & \\
\hline & C & 3 & 3 & 3 & 3 & \\
\hline & $u_{P n}$ & 3 & 2 & 3 & 3 & \\
\hline & $X_{P_{n}}$ & 12 & 21 & 33 & 45 & \\
\hline & $Y_{P n}$ & 12 & 9 & 12 & 12 & \\
\hline \multirow{8}{*}{3} & $P I_{P n}$ & 3 & 2 & 3 & 4 & \multirow{8}{*}{47} \\
\hline & $A P I_{P n}$ & 3 & 2 & 3 & 4 & \\
\hline & $A P I_{\min }$ & 1 & 1 & 1 & 1 & \\
\hline & $A P I_{\max }$ & 4 & 4 & 4 & 4 & \\
\hline & C & 1 & 1 & 1 & 1 & \\
\hline & $u_{P n}$ & 3 & 2 & 3 & 4 & \\
\hline & $X_{P n}$ & 12 & 21 & 33 & 47 & \\
\hline & $Y_{P n}$ & 12 & 9 & 12 & 14 & \\
\hline
\end{tabular}

The objective function will achieve the maximum value when the control domain takes the largest possible number of adequate performance indicators by performance (Simulation 3). This simple, flexible, low-cost, and adjustable model is suitable for SMEs that do not have enough financial resources for expensive software solutions used for defining a set of adequate performance indicators for production management improvement. The spreadsheet model can be implemented in all manufacturing SMEs, for a particular phase of production management, with a significant impact on its effectiveness. The full efficiency and effectiveness of the model imply adjustment to the needs and capabilities of the particular manufacturing company and its business environment. 


\section{Conslusion}

The basic contribution of this paper is the model developed for measuring the adequacy of selected performance indicators in the first phase of production management - planning. The performances and their indicators are defined according to the literature review, selecting the adequate ones for the planning phase. The model is developed for the production management of SMEs.

Future work can be directed toward a more systematic research of the model applicability to real-life problems of larger dimensions, i.e., the problem with an increased number of performances and performance indicators and additional constraints. Furthermore, the implementation of the model for all production management phases should be considered. Consequently, the adequacy of performance indicators for the whole production management process can be measured. Another interesting question comprises an adaptation of the model for large enterprises, where performances and performance indicators differ from those defined for SMEs.

\section{REFERENCES}

[1] Amrina, E., \& Vilsi, A. L. (2015). Key Performance Indicators for Sustainable Manufacturing Evaluation in Cement Industry. Procedia Cirp, 26(1), 19-23. DOI: 10.1016/j.procir.2014.07.173

[2] Antic, S., \& Djordjevic, L. (2018). Control Models and Applications in Spreadsheets (in Serbian: Upravljački modeli i aplikacije u spredšitovima). In: Benković S. (Eds) Finansijski menadžment, kontrola $i$ menadžersko računovodstvo. Belgrade: Faculty of Organizational Sciences, 234-266.

[3] Atanasov, N., Rakicevic, Z., Lecic-Cvetkovic, D., \& Omerbegovic-Bijelovic, J. (2014). An Approach to Stock Cover Indicator Adequacy. In Management: Journal Of Sustainable Business And Management Solutions In Emerging Economies, 19(73), 41-47. DOI:10.7595/management.fon.2014.0026

[4] Atanasov, N. (2016). A Model for Selecting Adequate Set of Performance Indicators in Production Management (in Serbian: Model za izbor adekvatnog skupa indikatora performansi u upravljanju proizvodnjom). Doctoral dissertation, Belgrade: Faculty of Organizational Sciences.

[5] Bauer, J. \& Hayessen, E. (2015). 100 Production Ratios. Cometis, Cometos Publishing, Germany.

[6] Bhatti, M. I., Awan, H. M., \& Razaq, Z. (2014). The Key Performance Indicators (KPIs) and Their Impact on Overall Organizational Performance. Quality \& Quantity, 48(6), 3127-3143. DOI: 10.1007/s11135-0139945-y

[7] Broman, K. W., \& Woo, K. H. (2018). Data Organization in Spreadsheets. In The American Statistician, 72(1), 2-10. DOI: 10.1080/00031305.2017.1375989

[8] Dajic, M., \& Todic, M. (2017). Measuring and Improving Key Performance Indicators in Today's Companies (in Serbian: Merenje i unapredjenje indikatora ključniih performansi u savremenim kompanijama). Anali poslovne ekonomije, 9(16), 52-59. DOI: 10.7251/APE1617052D

[9] Djordjevic, L. (2016). Error Detection and Analysis in Implementation of Dynamic Discrete Inventory Control Models (in Serbian: Detekcija i analiza grešaka u implementaciji dinamičkih diskretnih modela upravljanja zalihama). Doctoral dissertation, Belgrade: Faculty of Organizational Sciences.

[10] Djordjevic, L. (2017). Spreadsheet Engineering in the Context of Detecting and Fixing Errors in Dynamic Discrete Control Models (in Serbian: Spredšit inženjerstvo u kontekstu detekcije i ispravke grešaka u dinamičkim diskretnim upravljačkim modelima), monography. Belgrade: Andrejevic Foundation (Belgrade: Instant system).

[11] Djordjevic, L., \& Antic, S. (2014). Evaluating the Quality of the Analytical Spreadsheet Model (in Serbian: Ocena kvaliteta analitičkog spredšit modela). In Proceedings of YU INFO 2014, 206-211.

[12] Franceschini, F., Galetto, M., \& Maisano, D. (2006). Classification of Performance and Quality Indicators in Manufacturing. International Journal of Services and Operations Management, 2(3), 294-311.

[13] Franceschini, F., Galetto, M., \& Maisano, D. (2019). Designing Performance Measurement Systems-Theory and Practice of Key Performance Indicators. Management for Professionals.

[14] Gomes, C. F., Yasin, M. M., \& Lisboa, J. V. (2011). Performance Measurement Practices in Manufacturing Firms Revisited. International Journal of Operations \& Production Management, 31(1), 5-30. DOI: 10.1108/01443571111098726

[15] Gosselin, M. (2005). An Empirical Study of Performance Measurement in Manufacturing Firms. International Journal of Productivity and Performance Management, 54(5-6), 419-437. DOI: 10.1108/17410400510604566

[16] Graca, P., \& Camarinha-Matos, L. M. (2017). Performance Indicators for Collaborative Business Ecosystems-Literature Review and Trends. Technological Forecasting and Social Change, 116, 237-255. DOI: 10.1016/j.techfore.2016.10.012 
[17] Grossman, T. A., Mehrotra, V., \& Sander, J. (2011). Towards Evaluating the Quality of a Spreadsheet: The Case of the Analytical Spreadsheet Model. arXiv preprint arXiv:1111.6907.

[18] Gudmundsson, H., Marsden, G., \& Josias, Z. (2016). Sustainable Transportation: Indicators, Frameworks, and Performance Management. Heidelberg: Springer.

[19] Gupta, S., \& Starr, M. (2014). Production and Operations Management Systems. CRC Press.

[20] Halevi, G. (2001). Handbook of Production Management Methods. Elsevier.

[21] Hermans, F., Jansen, B., Roy, S., Aivaloglou, E., Swidan, A., \& Hoepelman, D. (2016). Spreadsheets are Code: An Overview of Software Engineering Approaches Applied to Spreadsheets. In Proceedings of 2016 IEEE 23rd International Conference on Software Analysis, Evolution, and Reengineering (SANER), 56-65. DOI: 10.1109/SANER.2016.86

[22] Jannach, D., \& Schmitz, T. (2016). Model-Based Diagnosis of Spreadsheet Programs: A Constraintbased Debugging Approach. Automated Software Engineering, 23(1), 105-144. DOI: 10.1007/s10515014-0141-7

[23] Kang, N., Zhao, C., Li, J., \& Horst, J. A. (2016). A Hierarchical Structure of Key Performance Indicators for Operation Management and Continuous Improvement in Production Systems. International Journal of Production Research, 54(21), 6333-6350. DOI: 10.1080/00207543.2015.1136082

[24] Muchiri, P., Pintelon, L., Gelders, L., \& Martin, H. (2011). Development of Maintenance Function Performance Measurement Framework and Indicators. International Journal of Production Economics, 131(1), 295-302. DOI:10.1016/j.ijpe.2010.04.039

[25] Omerbegovic-Bijelovic, J. (2006). Planning and Preparation of Production and Services (in Serbian: Planiranje i priprema proizvodnje i usluga). Belgrade: Faculty of Organizational Sciences.

[26] Ragsdale, C. (2018). Spreadsheet Modeling and Decision Analysis: A Practical Introduction to Business Analytics, $8^{\text {th }}$ Edition. USA: Cengage.

[27] Rajkovic, T., Makajic-Nikolic, D., Vujosevic, M., \& Lecic-Cvetkovic, D. (2019). Production Management by Application of Appropriate Performance Indicators (in Serbian: Upravljanje proizvodnjom primenom adekvatnih indikatora performansi). In Proceedings of XLVI International Symposium on Operational Research SYM-OP-IS 2019, 524-529.

[28] Rajkovic, T., \& Lecic-Cvetkovic, D. (2018). Usage of RFID Technology in Production Management. In Proceedings of 37th International Conference on Organizational Science Development, 923-933. DOI: 10.18690/978-961-286-146-9

[29] Roy, S., Hermans, F., \& van Deursen, A. (2017). Spreadsheet Testing in Practice. In Proceedings of 2017 IEEE 24 $4^{\text {th }}$ International Conference on Software Analysis, Evolution and Reengineering (SANER), 338-348. DOI: 10.1109/SANER.2017.7884634

[30] Simeunovic, B. (2015). Development Of Process Performance Measurement Model (in Serbian: Razvoj modela za merenje performansi procesa). Doctoral dissertation, Belgrade: Faculty of Organizational Sciences.

[31] Teixeira, R., \& Amaral, V. (2016). On the Emergence of Patterns for Spreadsheets Data Arrangements. In Federation of International Conferences on Software Technologies: Applications and Foundations, 333-345. Springer, Cham.

[32] Tewari, D., Singh, A., \& Tewari, P. C. (2016). Ranking of Performance Indicators in JIT-Based Production System for Manufacturing Industries. IUP Journal of Operations Management, 15(1), 25-34.

[33] Todorovic, J. M. (1993). Modern Production (in Serbian: Savremena proizvodnja). Belgrade: Mrljes.

[34] Villa, A., \& Taurino, T. (2018). Event-driven Production Scheduling in SME. Production Planning \& Control, 29(4), 271-279. DOI: 10.1080/09537287.2017.1401143

[35] Zach, O., Munkvold, B. E., \& Olsen, D. H. (2014). ERP System Implementation in SMEs: Exploring the Influences of the SME Context. Enterprise Information Systems, 8(2), 309-335. DOI: $10.1080 / 17517575.2012 .702358$

Received: 2020-02-06

Revisions requested: 2020-03-23

Revised: 2020-05-04 (2 revisions)

Accepted: 2020-06-09 


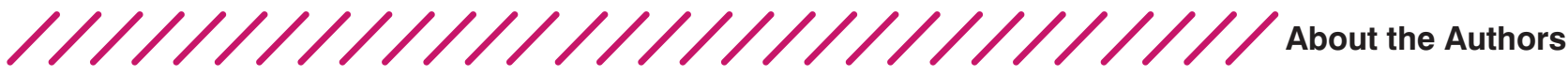

\author{
Teodora Rajković \\ University of Belgrade, Faculty of Organizational Sciences, Serbia \\ teodora.rajkovic@fon.bg.ac.rs
}

Teodora Rajković, MSc, is a teaching assistant at the Department for Production and Services Management of the Faculty of Organizational Sciences, University of Belgrade. Her research interests are related to operations management, production and services management, key performance indicators, e-manufacture and e-service. The author has published more than 10 papers in national and international conference proceedings.

\section{Lena Đorđević Milutinović \\ University of Belgrade, Faculty of Organizational Sciences, Serbia lena.djordjevic.milutinovic@fon.bg.ac.rs}

Lena Đorđević Milutinović, $\mathrm{PhD}$, is an assistant professor at the Department for Production and Services Management of the Faculty of Organizational Sciences, University of Belgrade. Her research interests include operations management, production and services management, spreadsheet engineering, spreadsheet management, material flow management, control systems, enterprise information systems and business applications. She has published over 70 papers in national and international scientific journals and conference proceedings, national and international scientific journals and conference proceedings chapters in national and international monographs, textbooks, and auxiliary teaching literature.

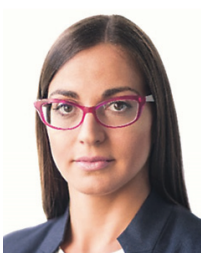

Danica Lečić-Cvetković University of Belgrade, Faculty of Organizational Sciences, Serbia danica.lecic-cvetkovic@fon.bg.ac.rs

Danica Lečić-Cvetković, PhD, is a full professor of Production and Services Management and e-Manufacturing at the Department for Operations Management, Faculty of Organizational Sciences, University of Belgrade. Her research interests and fields are related to operations management, production and services management, key performance indicators, e-manufacture and e-service. The author has published more than 100 papers in journals and conference proceedings in international and national journals and conferences. Since 2008, she is a member and leader of the MESA

(Manufacturing Enterprise Solutions Association) group for the Republic of Serbia.
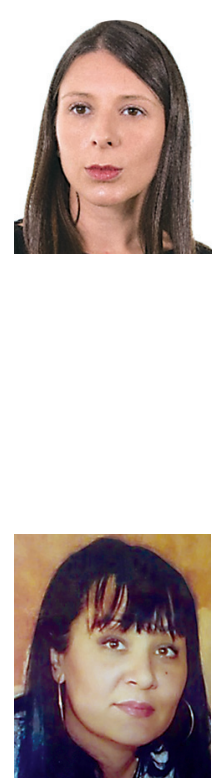